\title{
The characteristics of risk factors in Chinese young women with acute coronary syndrome
}

\author{
Ruifang Liu', Fangxing Xu', Yujie Zhou' and Tongku Liu ${ }^{2 *}$
}

\begin{abstract}
Background: In recent years, the prevalence rate of acute coronary syndrome (ACS) in Chinese young women has been increasing significantly, becoming one of the main causes of death in young females. A matter of constant concern is what is the characteristics and differences in risk factors between young women with ACS and without ACS. This study aimed to investigate the characteristics and difference of risk factors in Chinese young women with ACS and to provide references for ACS prevention and treatment.
\end{abstract}

Methods: A 1:1 case-control study was conducted to evaluate risk factors of 415 young females with ACS (ACS group) who underwent PCI treatment and 415 young females without ACS (control group) who were hospitalized and confirmed by coronary angiography to exclude coronary heart disease from January 2010 to August 2016. The average age of the cases in groups was respectively $(40.77 \pm 4.02)$ and $(40.57 \pm 4.01)$ years-old $(P>0.05)$.

Results: The risk factors in ACS group were overweight (64.10\%), hypertension (49.88\%), hyperlipidemia (40.72\%), diabetes (23.37\%), depression or anxiety (16.63\%), gynecological diseases (16.39\%), Hyperuricemia (14.94\%), family history of early-onset CHD (14.94\%), hyperhomocysteinemia (11.33\%), hypothyroidism (9.64\%), hypercholesterolemia (8.43\%) and high C-reactive protein $(7.47 \%)$, and were significant difference $(P<0.01)$ compared with that of the control group. The average number of risk factors per case in ACS group was significantly more than that of control groups $(P<0.01)$. Regression analysis showed that hyperlipidemia, hyperhomocysteinemia, overweight (obesity), high CRP, hypertension, hypothyroidism, gynecological diseases, depression or anxiety, cardiac insufficiency, hypercholesterolemia, diabetes, oral contraceptives, family history of early-onset CHD, and autoimmune diseases were independent risk factors $(P<0.01)$. The bivariate correlation analysis between CRP level and age was $r=-$ $0.158(P<0.01)$. The result showed the younger ACS patient is the higher serum CRP.

Conclusion: The independent risk factors of ACS in young women are hyperlipidemia, hyperhomocysteinemia, overweight, high CRP, hypertension, hypothyroidism, gynecological diseases, depression or anxiety, cardiac insufficiency, hypercholesterolemia, diabetes, oral contraceptives, family history of early-onset CHD, and autoimmune diseases. The co-existence of multiple risk factors is the main cause suffering from ACS in young women.

Keywords: Young women, Coronary artery disease, Acute coronary syndrome, Risk factors

\footnotetext{
*Correspondence: liutongku1014@163.com

${ }^{2}$ The Center of Cardiology, Affiliated Hospital of Beihua University, Jilin

132011 Jilin, People's Republic of China

Full list of author information is available at the end of the article
}

\section{$\triangle B M C$}

(c) The Author(s). 2020 Open Access This article is licensed under a Creative Commons Attribution 4.0 International License, which permits use, sharing, adaptation, distribution and reproduction in any medium or format, as long as you give appropriate credit to the original author(s) and the source, provide a link to the Creative Commons licence, and indicate if changes were made. The images or other third party material in this article are included in the article's Creative Commons licence, unless indicated otherwise in a credit line to the material. If material is not included in the article's Creative Commons licence and your intended use is not permitted by statutory regulation or exceeds the permitted use, you will need to obtain permission directly from the copyright holder. To view a copy of this licence, visit http://creativecommons.org/licenses/by/4.0/ The Creative Commons Public Domain Dedication waiver (http://creativecommons.org/publicdomain/zero/1.0/) applies to the data made available in this article, unless otherwise stated in a credit line to the data. 


\section{Background}

Coronary heart disease (CHD) is a major disease threatening women's health and life safety. Epidemiological investigations have shown that acute coronary syndrome (ACS) is one of the leading causes of death in women [1]. Because of the effect of estrogen, the onset age of $\mathrm{CHD}$ for women is 10 years later than that of men, and the occurrence of severe clinical events (such as myocardial infarction or sudden death) is 20 years later than that of men [2]。 In the last 20 years, the annual mortality rate for young women with $\mathrm{CHD}$ has increased by an average of $1.3 \%[3,4]$ 。 .

In this paper, the age division of peoples is based on the new age segmentation proposed by the World Health Organization in 2017.The age of young people is 44 and under 44 years old, middle-aged people are between 45 and 59 years old, young elderly people are between 60 and 74 years old, elderly people is between 75 and 89 years old, and the old longevity people is above 90 years old. The risk factors of CHD in young women under 44 years old have different characteristics [5]. The characteristics of risk factors in Chinese young women with ACS were reported in the article.

\section{Methods}

\section{Clinical data and grouping}

A retrospective 1:1 case-control study was conducted to evaluate risk factors of 415 young female patients with ACS (ACS group) who underwent percutaneous coronary intervention (PCI) treatment and stenting, and 415 young female cases (control group) who were hospitalized and underwent coronary angiography (CAG) to exclude coronary heart disease from January 2010 to August 2016. The age of the recruited patients was 44 years old or younger with the range from 19 to 44 years old. The average age of the cases in the two groups was respectively $(40.77 \pm 4.02)$ years-old and $(40.57 \pm 4.01)$ years-old $(P>0.05)$. The matched age conforms to the requirements of the case-control study. The Age, body mass index (BMI), personal history, past medical history, the results of physical and laboratory examination, New York Heart Association (NYHA) cardiac function class, and so on were recorded on admission and during hospitalization.

\section{Diagnostic criteria}

The diagnostic criteria of ACS met the requirements described in the American College of Cardiology / American Heart Association and European Society of Cardiology guidelines for the management of patients with non-ST-elevation and ST-segment elevation ACS [5-8]. The patients with ACS were at least one coronary artery stenosis of $75 \%$ or more in vessel diameter, or complete occlusion of infarction relative artery (IRA) confirmed by coronary angiography. The completely blocked IRA was defined as the blood flow of the Thrombolysis in Myocardial Infarction (TIMI) 0-1 grade. In the ACS group, there were 304 cases (73.25\%) with unstable angina pectoris, 28 cases (6.75\%) with non-ST-segment elevation acute myocardial infarction (NSTEMI), and 83 cases $(20.00 \%)$ with acute STsegment elevation myocardial infarction (STEMI). The cases in the control group were all patients without typical chest pain and received coronary angiography examination, which showed coronary artery was no stenosis or diameter stenosis of less than $50 \%$. The classification of cardiac function was diagnosed according to NYHA classification criteria [9]. The diagnostic criteria of renal insufficiency meet the standard of the National Kidney Foundation K/DOQI Clinical Practice Guidelines [10]. The patients with renal insufficiency were all in the compensatory period.

\section{The judging criteria for risk factors}

(1) Body-mass index (BMI) is equal to weight $(\mathrm{kg}) /$ height $\left(\mathrm{m}^{2}\right)$ squared. Overweight is defined as $\mathrm{BMI} \geq 24$ (WHO's recommendation for BMI normal range is $(18.5-23.0 \mathrm{~kg} / \mathrm{m} 2)$ for Asians and overweight is $\mathrm{BMI} \geq$ 24) [11]. (2) PCI history refers to that the patients received PCI treatment at any time before admission. (3) Family history of early-onset CHD refers to that the patients suffered from CHD or died of CHD or of unknown causes before the age of 50. (4) Smoker refers to that the patient was smoking within the past week or smoking on admission. (5) The patients who had suffered from hypertension in the past and had been treated with antihypertensive drugs were recorded as having hypertension. (6) The hyperlipidemia was defined as that the patient had suffered from hyperlipidemia, was taking lipid-lowering drugs, or that anyone of total cholesterol (TC), triglyceride (TG) and low-density lipoprotein cholesterol (LDL) of fasting venous plasma had exceeded the normal reference limit at the first time on admission. (7) $\mathrm{TC}>6.0 \mathrm{mmol} / \mathrm{L}$ at the first time on admission was recorded as hypercholesterolemia.(8) Plasma homocysteine (Hcy) $>15 \mathrm{umol} / \mathrm{L}$ was recorded as hyperhomocysteinemia. (9)C-reactive protein $(\mathrm{CRP})>10$ $\mathrm{mg} / \mathrm{L}$ was recorded as high CRP; (10) Hemoglobin (HB) $<110 \mathrm{~g} / \mathrm{L}$ was recorded as anemia. (11) It was recorded as diabetes that the patient has been diagnosed with diabetes before admission, or is receiving hypoglycemic drug treatment, or is the fasting venous blood glucose value $\geq 7.0 \mathrm{mmol} / \mathrm{L}$ on admission. (12) It was recorded as menopausal that the patient had not menstruated for 3 months or more. (13) The patients with cardiac insufficiency refers to the these whose the New York Heart Association cardiac function (NYHA) classification was 2 to 4 class, or the left ventricular ejection fraction 
measured by echocardiography was less than $50 \%$ and the diastolic left ventricular inner diameter was greater than $53 \mathrm{~mm}$. (14) The serum creatinine (SCr) level > 133 $\mathrm{mmol} / \mathrm{L}$ on admission or evaluated Glomerular Filtration Rate (eGFR) $<90 \mathrm{ml} / \mathrm{min} / 1.73 \mathrm{~m}^{2}$ (evaluated by using CockcroftGault equation from serum creatinine levels) [12] was recorded as chronic renal insufficiency (In the study eGFR of the patients with chronic renal insufficiency were $60-89 \mathrm{ml} / \mathrm{min} / 1.73 \mathrm{~m}^{2}$ ). (15) The uric acid value $>375 \mathrm{umol} / \mathrm{L}$ on admission was recorded as hyperuricemia. (16) It was recorded as renal artery stenosis that the patients with high blood pressure and with one or bilateral renal artery blood vessel diameter stenosis $\geq 50 \%$ by renal artery color ultrasound or by CT renal artery vascular imaging or by invasive renal artery angiography or by undergoing renal artery stent implantation.(17) It was recorded as hypothyroidism that patient suffered from hypothyroidism and was taking thyroid hormone therapy or plasma thyroxine level was lower than the normal level, and thyrotrophin was elevated at the same time.(18) It was recorded as an autoimmune disease that patient suffered from autoimmune disease in the past week and was taking related drugs treatment.(19) If the patients had been diagnosed with depression or anxiety previously and were taking antidepressant medication, these patients were recorded as having depression or anxiety. (20) It was recorded as gynecological diseases that the patient had been diagnosed as gynecological diseases on admission or ago, and was treated to be taking medication.(21) The patients admitted to be on oral contraceptives were recorded as being on oral contraceptives.

\section{Exclusion criteria}

The patients with the following conditions shall not be included in the study: (1) The acute myocardial infarction caused by coronary artery bypass graft (bridging vessel) lesions; (2) The acute myocardial infarction because of coronary aneurysm; (3) Patients with uncontrolled local or systemic infectious diseases; (4) Patients with malignant tumors; (5) Patients with hematologic disorders, such as hemophilia, thrombocytopenia, moderate or severe anemia $(\mathrm{HB} \leq 80 \mathrm{~g} / \mathrm{L}$ or $\mathrm{HB} \leq 60 \mathrm{~g} / \mathrm{L})$, and (6) STEMI patients who refuse PCI.

\section{CAG and PCI methods}

The Femoral artery or radial artery approach was adopted for CAG and PCI. CAG was performed according to conventional cardiac interventional techniques. CAG video was carefully read by two qualified interventional cardiologists to determine that the culprit coronary vessels were suitable for PCI. After the patient signed the informed consent, the heparin sodium was supplemented to $100 \mathrm{units} / \mathrm{kg}$, and PCI was performed as a routine method.

\section{Perioperative medication during $\mathrm{PCl}$}

$4000 \mathrm{u}$ of heparin sodium was routinely injected by intravenous bolus during CAG. Loading dose of $300 \mathrm{mg}$ of aspirin and $600 \mathrm{mg}$ of clopidogrel hydrogen sulfate were routinely administered orally before or after PCI". After CAG was performed the heparin sodium was supplemented to $100 \mathrm{u} / \mathrm{Kg}$ for patients with ACS-PCI. Heparin sodium $1000 \mathrm{u}$ was supplemented by intravenously when the PCI procedure was lasting for every $1 \mathrm{~h}$. The whole blood activation coagulation time $(\mathrm{ACT}) \geq 350 \mathrm{~s}$ was maintained until PCI was completed.

\section{Success criteria of PCI}

Successful PCI was defined as that after drug eluting stent (DES) implantation, the residual stenosis of the target coronary vessel segment was less than $10 \%$, and the forward blood flow in the target lesion vessel reached TIMI 3 grade [13], and no death and no acute myocardial infarction occurred during PCI. The subjects in the ACS group were all successful PCI.

\section{Statistical analyses}

The sample size of this study was calculated by using Power Analysis and Sample Size software (PASS, v 11.0.10, developed by NCSS, LLC, Kaysville, Utah, USA). According to the statistics principle and the epidemiology research theory in the multi-factor analysis, body mass index (BMI) was used as the exposure index to calculate sample size. The following statistical parameters were prepared by referring to the relevant literature and were input into the computer PASS software. After setting all statistical parameters, the sample size was got from PASS automatic calculation. The parameters were shown as follows: power $(1-\beta)$ is equal to $0.80, \beta$ is equal to 0.20 , alpha (significance level) is equal to $0.05, \mathrm{M}$ (number of controls per case) is equal to $1, \mathrm{P0}$ (probability that a control is exposed) is equal to 0.10 and $\mathrm{OR}$ value is equal to 2.0. The sample size of 369 cases (that is at least sample size) was got form output result. Since it was a 1:1 case-control study, the sample sizes of the two groups were equal, that is $369+369=738$ cases. In the period of case collection (from January 2010 to $\mathrm{Au}$ gust 2016) there were 434 patients with ACS - PCI who initially met the inclusion criteria. Among them 19 patients were excluded ( 5 patients with acute myocardial infarction and with coronary aneurysm, 8 patients with moderate or severe anemia $(\mathrm{HB} \leq 80 \mathrm{~g} / \mathrm{L}$ or $\mathrm{HB} \leq 60 \mathrm{~g} / \mathrm{L})$ because of functional uterine bleeding, and 6 STEMI patients who refuse PCI because the chest pain had eased on admission). Final total 415 of 434 cases with ACS were selected consecutively as ACS group. Within the 
same recruitment time, 415 cases without the coronary artery disease confirmed by CAG examination were selected as control group. The final number of recruited patients in each group, 415 cases, were much more than the minimum sample size, 369 cases in each group.

The data statistical analyses were performed using the Statistical Package for Social Sciences software (SPSS, version 20.0, SPSS Inc. Chicago, IL, USA). All data of cases were input into the computer software database. The continuous variables with normal distributions were expressed as mean \pm standard deviation. The comparisons between groups were performed using the independent Student's t-test. The counting data were expressed as a percentage (\%), and the chi-square $\left(\mathrm{X}^{2}\right)$ test was used for comparison between groups. Risk factors were analyzed by Logistic regression. The relationship between CRP level and age was analyzed by using Bivariate Correlation Analysis. The test level was set as a double-tail test $a=0.05 . P<0.05$ was statistically significant, and $P<0.01$ was statistically very significant.

\section{Results}

Comparative analysis of age and risk factors between the two groups

The age of patients in the ACS group and in the control group was respectively $(40.77 \pm 4.02)$ years-old and $(40.57 \pm 4.01)$ years-old, and was no significant difference compared between two groups $(P>0.05)$. There was no significant difference in age distribution between the two groups $(\mathrm{P}>0.05)$ (see Table 1$)$ 。 The distribution strength of risk factors in ACS group was overweight (64.10\%), hypertension (49.88\%), hyperlipidemia $(40.72 \%)$, diabetes (23.37\%), depression or anxiety disorder (16.63\%), gynecological diseases (16.39\%), hyperuricemia (14.94\%), family history of early-onset CHD (14.94\%), high homocysteine $(11.33 \%)$, low thyroid function $(9.64 \%)$, high cholesterol (8.43\%), high $\mathrm{C}$ - reactive protein $(7.47 \%)$, and was significant difference compared between the two groups $(P<$ 0.01). Other risk factors account for a smaller proportion (see Table 2). The baseline data of coronary angiographic characteristics and stents implantation in ACS group was showed in Additional files: Supplemental data Table 1.

\section{The number distribution of combined risk factors in the} two groups (see Table 3)

Table 3 shows the number of combined risk factors per case. Zero is no risk factor, and $1-7$ is the number of combined risk factors. As shown in Table 3, in the control group, $77.35 \%$ of individuals had no risk factors, only $22.65 \%$ of cases had 1-3 risk factors. Among the patients in the ACS group, only $7.95 \%$ had no risk factors, $54.70 \%$ had 2 to 3 risk factors, $85.79 \%$ had 1 to 4 risk factors, and $92.05 \%$ had 1 to 7 risk factors. The number of combined risk factors was statistically significant compared between the two groups $(P<0.01)$.

\section{Combined risk factors of overweight cases}

Overweight is the first risk factor of ACS for young women. In the ACS group, 266 (64.10\%) patients were overweight (obese). The proportion of overweight combined risk factors was shown in Table 4. As can be seen from Table 4, among 266 overweight patients in the ACS group there was no alone overweight (obese), while 98.13\% of the overweight cases were combined with 1 to 5 other risk factors, and $1.50 \%$ cases with six risk factors and $0.38 \%$ case with seven risk factors. In the control group, there were only 69 cases with overweight. Among 69 cases, $6(8.70 \%)$ had no combination of any risk factors, $89.86 \%$ had a combination of 1 to 2 risk factors, and $1.45 \%$ had combination of 3 risk factors. There was a statistically significant difference in the distribution of combined risk factors of overweight cases compared between the two groups $(P<0.05)$. The proportion distribution of the patients with different degrees of obesity in two groups was showed in Additional files: Supplemental data Table 2.

\section{Comparison of blood biomarkers in different group (see Table 5)}

It can be seen from Table 5 that there was no significant difference in $\mathrm{HB}(\mathrm{g} / \mathrm{L}), \mathrm{TC}(\mathrm{mmol} / \mathrm{L})$, and Uric $(\mathrm{mmol} /$ L) compared between two groups $(P>0.05)$. Serum LDL (mmol/L), TG (mmol/L) and TC/HDL ratio, SCr (umol/ $\mathrm{L}), \mathrm{CRP}(\mathrm{mg} / \mathrm{L})$ and Hcy (ummol/L) in ACS group were significantly higher than that in control group $(P<0.05)$. However, the HDL/LDL ratio $(0.53 \pm 0.19)$ in the control group was significantly higher than that $(0.46 \pm 0.18)$ in the ACS group $(P<0.01)$. The TC/HDL ratio $(4.19 \pm$ $1.52)$ in the ACS group was significantly higher than that $(3.58 \pm 0.93)$ in the control group $(\mathrm{P}<0.01)$.

\section{Logistic regression analysis of ACS risk factors}

ACS as the dependent variable and the overweight, hypertension, hyperlipidemia, diabetes, depression or

Table 1 The age distribution between the two groups

\begin{tabular}{lllll}
\hline Age (years old) & $<30$ & $30-39$ & $40-44$ & mean \pm standard deviation \\
\hline ACS group, $\mathrm{n}(\%)$ & $12(2.89)$ & $90(21.69)$ & $313(75.24)$ & $40.77 \pm 4.02$ \\
Control group, $\mathrm{n}(\%)$ & $14(3.37)$ & $90(21.69)$ & $311(74.94)$ & $40.57 \pm 4.01$
\end{tabular}

Compared with the number of cases distribution in two groups, $X^{2}=0.160, P=0.923$. Compared with the mean number of patients in the two groups, $\mathrm{t}=0.725, p=0.468$ 
Table 2 Comparison of risk factors between ACS group $(n=415)$ and control group $(n=415)$

\begin{tabular}{|c|c|c|c|c|}
\hline & ACS group & Control group & $X^{2}$ value & $P$ value \\
\hline Overweight n (\%) & $266(64.10)$ & $69(16.63)$ & 194.250 & 0.000 \\
\hline Hypertension n (\%) & $207(49.88)$ & $46(11.08)$ & 147.378 & 0.000 \\
\hline Hyperlipidemia n (\%) & $169(40.72)$ & $13(3.13)$ & 171.27 & 0.000 \\
\hline Diabetes n (\%) & $97(23.37)$ & $17(4.09)$ & 65.079 & 0.000 \\
\hline Depression or anxiety n (\%) & $69(16.63)$ & $10(2.41)$ & 48.698 & 0.000 \\
\hline Gynecological diseases n (\%) & $68(16.39)$ & $9(2.17)$ & 49.813 & 0.000 \\
\hline Hyperuricemia n (\%) & $62(14.94)$ & $27(6.51)$ & 15.417 & 0.000 \\
\hline Family history of CHD n (\%) & $62(14.94)$ & $9(2.17)$ & 43.264 & 0.000 \\
\hline Hyperhomocysteinemia n (\%) & $47(11.33)$ & $4(0.96)$ & 38.628 & 0.000 \\
\hline Hypothyroidism n (\%) & $40(9.64)$ & $4(0.96)$ & 31.103 & 0.000 \\
\hline Hypercholesterolemia n (\%) & $35(8.43)$ & $7(1.69)$ & 19.662 & 0.000 \\
\hline High CRP n (\%) & $31(7.47)$ & $4(0.96)$ & 38.628 & 0.000 \\
\hline Anemia n (\%) & $33(7.95)$ & $15(3.61)$ & 7.164 & 0.011 \\
\hline Cardiac insufficiency n (\%) & $31(7.47)$ & $1(0.24)$ & 29.253 & 0.000 \\
\hline Smoking n (\%) & $27(6.51)$ & $12(2.89)$ & 6.054 & 0.021 \\
\hline History of PCI n (\%) & $25(6.02)$ & $0(0.00)$ & 25.776 & 0.000 \\
\hline Autoimmune diseases n (\%) & $21(5.06)$ & $4(0.96)$ & 11.919 & 0.001 \\
\hline Postmenopausal n (\%) & $18(4.34)$ & $4(0.96)$ & 9.152 & 0.004 \\
\hline Oral contraceptive n (\%) & $15(3.61)$ & $2(0.48)$ & 10.149 & 0.002 \\
\hline Renal insufficiency n (\%) & $10(2.41)$ & $0(0.00)$ & 10.122 & 0.002 \\
\hline Renal artery stenosis n (\%) & $4(0.96)$ & $0(0.00)$ & 4.019 & 0.124 \\
\hline
\end{tabular}

CHD coronary heart disease, CRP C-Reactive Protein, Family history of CHD Family history of early onset CHD, $P C$ l percutaneous coronary intervention

anxiety, gynecological diseases, high uric acid, family history of early-onset CHD, low thyroid function, chronic cardiac insufficiency, smoking, history of PCI therapy, autoimmune diseases, menopause, birth control pills, chronic renal insufficiency, renal artery stenosis as independent variables were generated into the equation to be analysis (see Table 6). The confidence interval of $95 \%$ of relative risk (RR) was respectively hyperlipidemia (12.21-46.94), high homocysteine (Hcy, 5.32-43.76), overweight (4.95-11.07), high CRP (3.22-35.82), high

Table 3 The distribution of risk factors number in ACS group $(n=415)$ and control group $(n=415)$

\begin{tabular}{lll}
\hline No. of risk factors & ACS group & Control group \\
\hline $0, n(\%)$ & $33(7.95)$ & $321(77.35)$ \\
$1, n(\%)$ & $88(21.21)$ & $72(17.35)$ \\
$2, n(\%)$ & $126(30.36)$ & $21(5.06)$ \\
$3, n(\%)$ & $101(24.34)$ & $1(0.24)$ \\
$4, n(\%)$ & $41(9.88)$ & $0(0.00)$ \\
$5, n(\%)$ & $20(4.82)$ & $0(0.00)$ \\
$6, n(\%)$ & $5(1.20)$ & $0(0.00)$ \\
$7, n(\%)$ & $1(0.24)$ & $0(0.00)$ \\
\hline
\end{tabular}

$\mathrm{X}^{2}=475.944, P=0.000$ blood pressure (2.80-6.87), low thyroid function (2.7931.13), gynecological diseases (2.59-14.23), depression or anxiety (2.40-12.71), cardiac insufficiency (2.25155.03), Hypercholesterolemia (2.23-12.21), diabetes (2.14-7.96), oral contraceptive (2.08-65.58), family history of early-onset CHD (1.66-9.86), and autoimmune diseases $(1.60-22.75)(P<0.01)$. (Detailed regression parameters are shown in Additional file: Supplementary data Table 3.)

Table 4 Distribution of combined risk factors of overweight cases in ACS group $(n=266)$ and control group $(n=69)$

\begin{tabular}{lll}
\hline Combined risk factors & ACS group & Control group \\
\hline $0, \mathrm{n}(\%)$ & $0(0.00)$ & $6(8.70)$ \\
$1, \mathrm{n}(\%)$ & $47(17.67)$ & $43(62.32)$ \\
$2, \mathrm{n}(\%)$ & $84(31.58)$ & $19(27.54)$ \\
$3, \mathrm{n}(\%)$ & $82(30.83)$ & $1(1.45)$ \\
$4, \mathrm{n}(\%)$ & $30(11.28)$ & $0(0.00)$ \\
$5, \mathrm{n}(\%)$ & $18(6.77)$ & $0(0.00)$ \\
$6, n(\%)$ & $4(1.50)$ & $0(0.00)$ \\
$7, n(\%)$ & $1(0.38)$ & $0(0.00)$ \\
\hline
\end{tabular}


Table 5 Comparison of biomarkers in different groups (mean \pm standard deviation)

\begin{tabular}{|c|c|c|c|c|}
\hline Biomarkers & ACS group & Control group & $x^{2}$ & $P$ value \\
\hline $\mathrm{HB}(\mathrm{g} / \mathrm{L})$ & $127.85 \pm 15.20$ & $129.39 \pm 12.10$ & 1.613 & 0.107 \\
\hline LDL (mmol/L) & $2.64 \pm 1.11$ & $2.46 \pm 0.63$ & 2.939 & 0.003 \\
\hline HDL (mmol/L) & $1.09 \pm 0.26$ & $1.24 \pm 0.35$ & 7.059 & 0.000 \\
\hline HDL/LDL & $0.46 \pm 0.18$ & $0.53 \pm 0.19$ & 4.892 & 0.000 \\
\hline $\mathrm{TG}(\mathrm{mmol} / \mathrm{L})$ & $1.81 \pm 1.57$ & $1.38 \pm 0.50$ & 5.239 & 0.000 \\
\hline $\mathrm{TC}(\mathrm{mmol} / \mathrm{L})$ & $4.36 \pm 1.33$ & $4.24 \pm 0.92$ & 1.432 & 0.153 \\
\hline $\mathrm{TC} / \mathrm{HDL}$ & $4.19 \pm 1.52$ & $3.58 \pm 0.93$ & 6.978 & 0.000 \\
\hline SCr (umol/L) & $63.40 \pm 19.32$ & $59.22 \pm 11.12$ & 3.755 & 0.000 \\
\hline Uric (umol/L) & $285.30 \pm 83.73$ & $277.15 \pm 66.48$ & 1.552 & 0.121 \\
\hline CRP (mg/L) & $3.40 \pm 5.98$ & $1.24 \pm 1.46$ & 7.124 & 0.000 \\
\hline Hcy (ummol/L) & $10.30 \pm 6.04$ & $8.46 \pm 2.45$ & 5.732 & 0.000 \\
\hline
\end{tabular}

\section{Bivariate correlation analysis between CRP level and age} The mean age of 830 cases was $(40.67 \pm 4.019)$ years old. The mean serum CRP of them was $(2.32+4.48) \mathrm{mg} / \mathrm{L}$. A Bivariate Correlation Analysis of CRP level and age yielded a Pearson Correlation of -0.127 and a $P$ value of 0.000 for the double-tailed test. This result indicates that the CRP level is negatively correlated with age; that is, the younger patient is the higher CRP level. This discovery indicates CRP plays a role in the pathogenesis of young female patients with ACS (See Additional file: Supplemental data Table 4).

Table 6 Multivariate Logistic regression analysis of ACS risk factors

\begin{tabular}{llll}
\hline Risk factors & $\mathrm{RR}$ & $95 \% \mathrm{Cl}$ & $P$ value \\
\hline Hyperlipidemia & 23.940 & $12.209-46.943$ & 0.000 \\
Homocysteinemia & 15.260 & $5.321-43.763$ & 0.000 \\
Overweight & 7.403 & $4.950-11.070$ & 0.000 \\
High CRP & 10.740 & $3.220-35.817$ & 0.000 \\
Hypertension & 4.384 & $2.799-6.869$ & 0.000 \\
Hypothyroidism & 9.323 & $2.792-31.133$ & 0.000 \\
Gynecological disease & 6.609 & $2.588-14.232$ & 0.000 \\
Depression or anxiety & 5.516 & $2.395-12.705$ & 0.000 \\
Cardiac insufficiency & 18.692 & $2.254-155.030$ & 0.000 \\
Hypercholesterolemia & 5.287 & $2.228-12.214$ & 0.000 \\
Diabetes & 4.125 & $2.138-7.958$ & 0.000 \\
Oral contraceptive & 11.684 & $2.082-65.581$ & 0.005 \\
Family history of CHD & 4.043 & $1.657-9.863$ & 0.002 \\
Autoimmune diseases & 6.023 & $1.595-22.746$ & 0.008 \\
\hline
\end{tabular}

CRP C-reactive protein, Family history of CHD Family history of early onset coronary heart disease, $R R$ relative risk, $95 \% C . I 95 \%$ confidence interval

\section{Discussion}

The intensity of risk factors in young women with ACS

Epidemiological studies have shown that hypertension, hyperlipidemia, smoking, and diabetes are the four major risk factors for coronary heart disease [14, 15]. The results of this study showed that the age of young women was $(40.77 \pm 4.02)$ years-old in ACS group and (40.57 \pm 4.01 ) years-old in the control group, and was no significant difference $(P>0.05)$ compared between two groups. The subjects in the control group received coronary angiography examination and were proved to be not the coronary artery lesion or to have only mild atherosclerotic plaque, and stenosis with less than $50 \%$ of coronary artery lumen diameter. The proportion of combined risk factors in the control group was significantly lower than that in the ACS group $(P<0.05)$. The risk factors in ACS group was respectively overweight (64.10\%), hypertension (49.88\%), hyperlipidemia (40.72\%), diabetes (23.37\%), depression or anxiety disorder (16.63\%), gynecological diseases (16.39\%), hyperuricemia (14.94\%), family history of early- onset coronary heart disease (14.94\%), hyperhomocysteinemia (11.33\%), low thyroid function (9.46\%), high cholesterol (8.43\%), high CRP (7.47\%). Other risk factors account for a smaller proportion (see Table 2). However, except for renal artery stenosis, there were statistically significant differences in the distribution of risk factors compared between $\operatorname{groups}(P<$ $0.01)$. These results are consistent with those of the Framingham Heart Study [16, 17]. The result of Framingham Heart Study showed the relative risk of coronary heart disease in obese women increased by $64 \%$ and was statistically significant differences compared with a $46 \%$ increase in men. The relationship between obesity and cardiovascular disease is becoming more and more clear [18]. The regression analysis in this study shows that the relative risk in obese (overweight) women with ACS was more than $400 \%$ of those in normal young women without $\operatorname{ACS}(P<0.01)$. The results of this study showed that $64.10 \%$ of cases with overweight in the ACS group were significantly higher than those (16.63\%) in the control group ( $\mathrm{P}<0.01)$. Of the 266 overweight (obese) patients in the ACS group, $98.13 \%$ were overweight with one to five risk factors $(\mathrm{P}<0.01)$. This result showed that the combination of multiple risk factors is one of the main causes of overweight cases with ACS. In addition to the four traditional risk factors of hypertension, hyperlipidemia, smoking, and diabetes, the regression analysis results showed that in young women, hyperhomocysteinemia, overweight /obesity, high CRP, hypothyroidism, gynecological diseases, depression or anxiety, cardiac insufficiency, and oral contraceptives, family history of early-onset CHD and autoimmune diseases are independent risk factors. This is the main characteristic of risk factors in young women with ACS [2]. In the ACS group, the distribution 
proportion of these risk factors was significantly higher than that in the control group $(P<0.01)$. Among the ACS patients in this study, $54.70 \%$ of cases were combination with 2 to 3 risk factors, and $85.79 \%$ were combination with 1 to 4 risk factors. There were statistically significant differences in the number of combined risk factors compared between the two groups $(P<0.01)$. This result indicates that the co-existence of multiple risk factors is the main cause for the occurrence of ACS in young women. It has been reported that gynecological diseases combined with cardiovascular disease (such as hypertension) and diabetes increase the risk of ischemic heart disease by two times [19]. The patients who smoke and also take oral contraceptives have a seven-fold increased risk of developing arteriosclerotic cardiovascular disease [20]。The results of this study also showed that the smoking rate of ACS patients was significantly higher than that of the control group $(P<0.05)$. Hyperuricemia is an independent risk factor in women with CHD, but not in men [21]。Estrogen has a protective effect on the heart [22, 23]. After menopause, estrogen secretion gradually decreases in women, which causes metabolic disorders and leads to increased blood lipids and increased blood viscosity, thus leading to atherosclerosis and significantly increasing the incidence of coronary heart disease [24]. So menopause is a unique risk factor for coronary heart disease in women [25].

The role of lipids, creatinine, uric acid, homocysteine and inflammatory reactions on the pathogenesis of ACS

The results of this study showed that the serum levels of LDL, TG, creatinine (Crea), CRP, and Hcy in the ACS group were significantly higher than those in the control group $(P<0.01)$. This showed that these factors are involved in the occurrence and development of ACS in young women [26]. The proportion of hyperlipidemia $(40.72 \%)$ in the ACS group was significantly higher than that $(3.13 \%)$ in the control group $(P<0.01)$. Hyperuricemia (14.94\%) in the ACS group was significantly higher than that $(6.51 \%)$ in the control group $(\mathrm{P}<0.01)$. The HDL/LDL ratio $(0.53 \pm 0.19)$ in the control group was significantly higher than that $(0.46 \pm 0.18)$ in the ACS group $(\mathrm{P}<0.01)$. The $\mathrm{TC} / \mathrm{HDL}$ ratio $(4.19 \pm 1.52)$ in the ACS group was significantly higher than that $(3.58 \pm$ $0.93)$ in the control group $(P<0.01)$. This indicates that lipids and uric acid are involved in the pathogenesis of ACS in young women $[27,28]$. Hcy has been proven to be a risk factor for coronary heart disease. Hcy level $(10.30 \pm 6.04 \mathrm{umol} / \mathrm{L})$ in the ACS group was significantly higher than that $(8.46 \pm 2.45 \mathrm{umol} / \mathrm{L})$ in the control group, with a statistically significant difference $(P<0.01)$ compared between two groups. This indicates that Hcy is also a risk factor suffering from ACS in young women.

The relationship between CRP and ACS is complex. CRP promotes the formation of unstable plaques of coronary atherosclerosis, and triggers the rupture of vulnerable plaques, cause thrombosis in coronary arteries and lead to the occurrence of ACS and acute myocardial infarction (AMI). CRP can reduce the stability of nitric oxide synthase mRNA in endothelial cells, which leads to the decrease of the expression of nitric oxide synthase protein and to inhibits endothelial cells to produce nitric oxide. Nitric oxide has the role of maintaining the elasticity of blood vessel, and dilating the blood vessels, being against vasoconstriction caused by endothelin and angiotensin II, and promoting the formation of blood vessels. CRP may also increase the expression of endothelial cell adhesion molecules and enzymatically bind to modified low-density lipoprotein, which promote monocyte aggregation into the atheromatous plaque to cause plaque instability. AMI necrosis substance stimulates the production of CRP. Therefore, the increase in CRP is proportional to the number of myocardial cells necrosis. CRP rises to the peak value in 2 days after the onset of AMI, and then drops gradually. The finding suggests that there is a causal relationship between CRP and the onset of ACS, and that CRP is an important risk factor for the onset of ACS in young women. This study showed that the average CRP $(3.40 \pm 5.98 \mathrm{mg} / \mathrm{L})$ in the ACS group was significantly higher than that $(1.24 \pm$ $1.46 \mathrm{mg} / \mathrm{L})$ in control group $(P<0.01)$. A bivariate correlation analysis of CRP level and age yielded a Pearson Correlation of -0.129 and a $P$ value of 0.000 as the double-tail test. This result showed that CRP level is negatively correlated with age; that is, the younger female is the higher CRP level, indicating the role of CRP on the occurrence and development of ACS in young females. Previous studies have shown that high sensitivity C-reactive protein (hs-CRP) elevation can predict future adverse cardiac events [29]. Anti-inflammatory drugs, such as colchicine, methotrexate, and IL-1 $\beta$ inhibitor canakinumab, can reduce the inflammatory response and significantly reduce the risk of cardiovascular events. The result confirms that the inflammatory response is involved in the occurrence and development of ACS.

\section{The limitations of this study}

This study has some limitations. The effect of the duration of exposure risk factors on the occurrence of ACS is still unclear. It is not clear how long the risk factors exposed last for before they become effective. Such unanswered questions are definitely requiring a further study to address.

\section{Conclusion}

Comprehensive above, can be concluded that: (1) the young female with ACS is to have risk factors of complex. Hyperlipidemia, high homocysteine, overweight, high CRP, hypertension, hypothyroidism, gynecological 
diseases, depression or anxiety, cardiac insufficiency, hypercholesterolemia, diabetes, oral contraceptive, family history of early -onset CHD, autoimmune diseases are independent risk factors for young women with ACS; (2) the co-existence of multiple risk factors is the main cause suffering from ACS in young women; (3) the overweight cases have a trend suffering from ACS because of the combination of multiple risk factors; (4) inflammatory response is involved in the pathogenesis of ACS in young women. It may reduce the prevalence of ACS in young women to treat those risk factors.

\section{Supplementary information}

Supplementary information accompanies this paper at https://doi.org/10. 1186/s12872-020-01577-z.

Additional file 1: Supplemental data table 1. Baseline data of coronary angiographic characteristics and stents implantation in ACS group. Supplemental data table 2. The BMI distribution of patients in the study. Supplemental data table 3. Multivariate Logistic regression analysis of ACS risk factors. Supplemental data table 4. A bivariate correlation analysis of CRP level and age.

\section{Abbreviations}

ACS: Acute coronary syndrome; ACT: Activation coagulation time; AMI: Acute myocardial infarction; BMI: Body mass index; CHD: Coronary heart disease; CT: Computed tomography; HB: Hemoglobin; Hcy: Homocysteine; HDL: Highdensity lipoprotein; Hs-CRP: High sensitivity C-reactive protein; IL: Interleukin; LDL: Low-density lipoprotein; NSTEMI: Non-STEMI; PCI: Percutaneous coronary intervention; RR: Relative risk; SCr: Serum creatinine; STEMI: STelevation myocardial infarction; TC: Total cholesterol; TG: Triglycerides; TIMI: Thrombolysis in myocardial infarction; UA: Unstable angina; Uric: Uric acid

\section{Acknowledgments}

The authors thank professors Yingxin Zhao and Yuyang Liu at the cardiac catheterization laboratory for their skilled technical assistance at Affiliated Beijing Anzhen Hospital, Capital Medical University.

\section{Authors' contributions}

RFL conceived and supervised the study, was involved in the $\mathrm{PCl}$ procedure and wrote the main body of the manuscript. FXX collected the clinic data and participated in the discussion on the interpretation of the research content. YJZ directed the drafting of the manuscript and critically revised the manuscript. TKL took part in the $\mathrm{PCl}$ procedure, performed statistical analysis of the data, and revised this paper. All authors critically revised and approved the final version of the manuscript.

\section{Funding}

The study was supported by the Cardiovascular Sunlight Research Fund of the Chinese Medical Association. This research project number is SCRFCMDA201214. The funders had no role in study design, data collection, and analysis, decision to publish, or preparation of the manuscript.

\section{Availability of data and materials}

The datasets used and/or analysed during the current study are available from the corresponding author on reasonable request.

\section{Ethics approval and consent to participate}

All participants provided written consent before entering the study according to the regulations of Beijing Anzhen hospital. The study was approved by the Ethics Committee of Beijing Anzhen Hospital, with the ethical approval number: EAN2016CLYJ0106.

\section{Consent for publication}

Not applicable.

\section{Competing interests}

The authors declare that the research was conducted in the absence of any commercial or financial relationships that could be construed as a potential conflict of interest.

\section{Author details}

'Department of Cardiology, Beijing Anzhen Hospital, Capital Medical University, Beijing 100029, People's Republic of China. ${ }^{2}$ The Center of Cardiology, Affiliated Hospital of Beihua University, Jilin 132011 Jilin, People's Republic of China.

Received: 22 March 2020 Accepted: 5 June 2020

Published online: 12 June 2020

\section{References}

1. He J, Gu D, Wu X, Reynolds K, Duan XF, Yao CH, et al. Major causes of death among men and women in China. N Engl J Med. 2005;353(11):1124-34.

2. Chandrasekhar J, Gill A, Mehran R. Acute myocardial infarction in young women: current perspectives. Int J Women's Health. 2018;10:267-84.

3. Virani SS, Alonso A, Benjamin EJ, Bittencourt MS, Callaway CW, Carson AP, et al. Heart disease and stroke statistics-2020 update: a report from the American Heart Association. Circulation. 2020;141:e139-596.

4. Hua D, Yu D. Epidemiology of cardiovascular disease in Asian women, Nutrition. Metab Cardiovasc Dis. 2010;20:394-404.

5. Wang X, Gao M, Zhou SS, Wang JW, Liu F, Tian F, et al. Trend in young coronary artery disease in China from 2010 to 2014: a retrospective study of young patients $\leq 45$. BMC Cardiovasc Disord. 2017;17(18):1-8.

6. O'Gara PT, Kushne FG, Ascheim DD, CaseyJr DE, Chung MK, de Lemos JA, et al. 2013 ACCF/AHA guideline for the management of ST-elevation myocardial infarction: executive summary: a report of the American College of Cardiology Foundation/American Heart Association task force on practice guidelines. J Am Coll Cardiol. 2013;61(4):e78-e140.

7. Amsterdam EA, Wenger NK, Brindis RG, Casey DE, Ganiats TG, Holmes DR, et al. 2014 AHA/ACC guideline for the management of patients with nonST-elevation acute coronary syndromes: executive summary: a report of the American College of Cardiology/American Heart Association task force on practice guidelines. Circulation. 2014;130(25):2354-94.

8. Arslan F, Bongartz L, ten Berg JM, Jukema JW, Appelman Y, Liem AH, et al. 2017 ESC guidelines for the management of acute myocardial infarction in patients presenting with ST-segment elevation: comments from the Dutch ACS working group. Neth Hear J. 2018;26:417-21.

9. Hunt SA, Abraham WT, Chin MH, Feldman AM, Francis GS, Ganiats TG, et al. ACC/AHA 2005 guideline update for the diagnosis and management of chronic heart failure in the adult-summary article: a report of the American College of Cardiology/American Heart Association task force on practice guidelines (writing committee to update the 2001 guidelines for the evaluation and management of heart failure). J Am Coll Cardiol. 2005; 46(6):1116-43.

10. Kopple JD. National Kidney Foundation K/DOQI clinical practice guidelines for nutrition in chronic renal failure. Am J Kidney Dis. 2001;37(Suppl 2):S66-70.

11. Patel JK, Hughes EA, Mackness MI, Vyas A, Cruickshank JK. Appropriate body-mass index for Asians. Lancet. 2003;361(9351):85.

12. Levey AS, Coresh J, Balk E, Kausz AT, Levin A, Steffes MW, et al. National Kidney Foundation practice guidelines for chronic kidney disease: evaluation, classification, and stratification. Ann Intern Med. 2003;139(2):137-47.

13. Braunwald E, Sabatine MS. The thrombolysis in myocardial infarction (TIMI) study group experience. J Thorac Cardiovasc Surg. 2012;144(4):762-70.

14. Patel SA, Winkel M, Ali MK, Narayan KM, Mehta NK. Cardiovascular mortality associated with 5 leading risk factors: national and state preventable fractions estimated from survey data. Ann Intern Med. 2015;163(4):245-53.

15. Vilahur G, Badimon JJ, Bugiardini R, Badimon L. Perspectives: The burden of cardiovascular risk factors and coronary heart disease in Europe and worldwide. Eur Heart J. 2014;16(suppl A):A7-A11.

16. Mahmood SS, Levy D, Vasan RS, Wang TJ. The Framingham heart study and the epidemiology of cardiovascular disease: a historical perspective. Lancet. 2014:383(9921):999-1008.

17. Andersson C, Johnson AD, Benjamin EJ, Levy D, Vasan RS. 70-year legacy of the Framingham heart study. Nat Rev Cardiol. 2019;16:687-98.

18. Adams B, Jacocks L, Guo H. Higher BMl is linked to an increased risk of heart attacks in European adults: a Mendelian randomisation study. BMC Cardiovasc Disord. 2020;20:258. https://doi.org/10.1186/s12872-020-01542-w. 
19. Brown HL, Warner JJ, Gianos E, Gulati M, Hill AJ, Hollier LM, et al. Promoting risk identification and reduction of cardiovascular disease in women through collaboration with obstetricians and gynecologists: a presidential advisory from the American Heart Association and the American College of Obstetricians and Gynecologists. Circulation. 2018;137(24):e843-52.

20. Hackshaw A, Morris JK, Boniface S. Low cigarette consumption and risk of coronary heart disease and stroke: meta-analysis of 141 cohort studies in 55 study reports. BMJ. 2018;363:k5035.

21. Skak-Nielsen H, Torp-Pedersen C, Finer N, Caterson ID, Van Gaal L, James WPT, et al. Uric acid as a risk factor for cardiovascular disease and mortality in overweight/obese individuals. PLoS One. 2013;8(3):e59121.

22. Venetkoski M, Savolainen-Peltonen H, Rahkola-Soisalo P, Hoti F, Vattulainen $\mathrm{P}$, Gissler $\mathrm{M}$, et al. Increased cardiac and stroke death risk in the first year after discontinuation of postmenopausal hormone therapy. Menopause. 2018;25(4):375-9.

23. Zhao D, Guallar E, Ouyang P, Subramanya V, Vaidya D, Ndumele CE, et al. Endogenous sex hormones and incident cardiovascular disease in postmenopausal women. J Am Coll Cardiol. 2018;71(22):2555-66.

24. Shaw LJ, Pepine CJ, Xie J, Mehta PK, Morris AA, Dickert NW, et al. Quality and equitable health care gaps for women: attributions to sex differences in cardiovascular medicine. J Am Coll Cardiol. 2017;70(3):373-88.

25. Greenwood BN, Carnahan S, Huang L. Patient-physician gender concordance and increased mortality among female heart attack patients. Proc Natl Acad Sci U S A. 2018;115(34):8569-74.

26. Liu HH, Dong Z, Ma CS, Liu XH, Lv Q, Qi Y, et al. C-reactive protein predicts the severity of coronary artery disease beyond low-density lipoprotein cholesterol. Angiology. 2012;63(3):218-22.

27. He C, Lin P, Liu W, Fang K. Prognostic value of hyperuricemia in patients with acute coronary syndrome: a meta-analysis. Eur J Clin Investig. 2019; 49(4):e13074.

28. Lv S, Liu W, Zhou Y, Liu Y, Shi D, Zhao Y, et al. Hyperuricemia and smoking in young adults suspected of coronary artery disease $\leq 35$ years of age: a hospital - based observational study. BMC Cardiovasc Disord. 2018;18(1):178

29. Badimon L, Peña E, Arderiu G, Padró T, Slevin M, Vilahur G, et al. C-reactive protein in atherothrombosis and angiogenesis. Front Immunol. 2018;9(2): 430-7.

\section{Publisher's Note}

Springer Nature remains neutral with regard to jurisdictional claims in published maps and institutional affiliations.

Ready to submit your research? Choose BMC and benefit from:

- fast, convenient online submission

- thorough peer review by experienced researchers in your field

- rapid publication on acceptance

- support for research data, including large and complex data types

- gold Open Access which fosters wider collaboration and increased citations

- maximum visibility for your research: over $100 \mathrm{M}$ website views per year

At $\mathrm{BMC}$, research is always in progress.

Learn more biomedcentral.com/submissions 